American Journal of Economics and Business Administration 3 (3): 490-497, 2011

ISSN 1945-5488

(C) 2011 Science Publications

\title{
Work Culture and Developing Agri-Entrepreneurial Skills among Farmers
}

\author{
${ }^{1}$ M. Zainalabidin, ${ }^{1}$ R. Golnaz, ${ }^{1}$ A. Ira, ${ }^{1}$ M.A. Amin and ${ }^{2}$ T. Ezhar \\ ${ }^{1}$ Department of Agribusiness and Information Systems, \\ Faculty of Agriculture, University Putra Malaysia, \\ 43400 UPM, Serdang, Selangor DE, Malaysia \\ ${ }^{2}$ Department of Communication, \\ Faculty of Modern Language and Communication, \\ University Putra Malaysia, 43400 Serdang, Selangor, Malaysia
}

\begin{abstract}
Problem statement: The government of Malaysia has established several agencies within the Ministry of Agriculture and agri-based Industry such as the Farmers' Organization Authority to provide technical and motivational training to individual members involved in farming practices to become agri-entrepreneurs. Approach: The objectives of the study are to identify and determine the entrepreneurial work culture as perceived by Farmers' Organization Authority members. Members of Farmers' Organization Authority were interviewed via a structured questionnaire. The factor analysis determines 6 latent factors that were realized by the Farmers' Organization Authority members as being important for promoting an entrepreneurial work culture and therefore should be enhanced and re-inculcated among the Farmers' Organization Authority farming community. Results: These factors translate into the community having to become more innovative, responsible and accountable, profit oriented, visionary, better at performing their study practices in a more systematic way and finally to become more self confident. Conclusion/Recommendation: Efforts should be intensified to encourage Farmers' Organization Authority members with training to focus not on modern technologies only, but on enhancing the entrepreneurial work culture and fundamental changes in attitude towards treating farming as a business. Formal entrepreneurship training should be instituted to all Farmers' Organization Authority members who are interested in taking a loan in enhancing their farming activities. This conditionality can be implemented to ensure that the loan is being spent accordingly and the development of agri-entrepreneurship skills can be enhanced.
\end{abstract}

Key words: Agri-entrepreneurship, FOA members, informal training, factor analysis, work culture, Farmers' Organization Authority (FOA)

\section{INTRODUCTION}

During the Ninth Malaysia Plan (2005-2009) (NMP) Ninth Malaysian Plan (NMP), a major objective for the country is for the agricultural sector be revitalized and to emerge as the third pillar of economic growth. The "new agriculture" program will be undertaken, which includes greater orientation towards more modern and commercial scale of agricultural produce, The production of high value added primary and agri-based products are encouraged and a wider application of Information and Communication Technology (ICT) to facilitate the market intelligence activities. In order to speed up the agricultural sector development the government also emphasis on the use of biotechnology for contributing to new wealth creation. At the same time the program will include promoting the use of better marketing approaches emphasizing products standards and farm accreditation, The introduction of a higher level of professionalism and the participation of entrepreneurial farmers and a skilled workforce is a way forward for the agriculture sector to move and become the pillar of economic growth.

The agricultural policies stated in the NMP have been set to reinforce the Third National Agricultural Policy (2000-2010) (NAP3) which was formulated in 1999 in conjunction with the formation of the Eighth Malaysia Plan (2000-2005). The NAP3 is built upon the strengths of the product-based and agri forestry strategic approaches to overcome the issues and

Corresponding Author: Zainalabidin Mohamed, Department of Agribusiness and Information Systems, Faculty of Agriculture, University Putra Malaysia, 43400, Serdang, Selangor DE, Malaysia Tel: +603 8946 4121/4141 
challenges that constrained the progress of the agricultural sector. In line with the policy to turn agriculture into a viable business, more vigorous efforts will be undertaken to develop new agricultural entrepreneurs to strengthen existing small and medium scale entrepreneurs as well as to promote agricultural exporters. In this regard, special training, credit facilities and technical assistance will be provided by the government. In order to spear head the entrepreneurship development program, the Ministry Of Agriculture and Agri-based Industry (MOA) has emphasized that agriculture is no more a traditional way of doing things nor is it a way of life but instead "Agriculture is Business".

The importance placed upon agriculture as one of the new engines of growth for Malaysia's economy can be seen through the sheer amount and variety of supporting mechanisms and policies that exist for agri-entrepreneurs. The budget for the NMP entrepreneurial development was RM 511.9 million (USD165.00 million) with a total of 9,390 new agri-entrepreneurs expected to be created. This development program has been put in place to enhance agriculture production so as to make Malaysia more competitive in the world market, to achieve a certain level of self sufficiency in food production and to reduce the balance of trade on food items.

However, the presence or creation of agrientrepreneurs seems to be lagging behind the existence of entrepreneurs from other sectors such as manufacturing and services. Since most of the farmers in Malaysia are not highly educated or may not have even had a formal education, they do not realize their potential as agrientrepreneurs or they do not recognize how their daily activities developed their entrepreneurial skills over time. Thus the objective of this study is to determine the factors or work culture which could be used to enhance and re-inculcate the development of entrepreneurship among the farmers. These factors can be used as focal points to motivate the farmers in a more structured manner in order to increase the agricultural sector's performance. It is inevitable that further reinculcation of the study culture is needed in order to strengthen capacity building among the farmers. In turn this should help to empower them so they are able to achieve sustainable growth in the agribusiness sector, in food production and to be successful and sustainable agri-entrepreneurs in the long run.

A review of the previous study on entrepreneurial work culture: Entrepreneurial skills are important because the concept of this skill implies the ability to innovate, motivate, be opportunist, be risk bearing, pursue in personality development, to be active in socializing within society and it is a long life learning process. In the psychological literature on entrepreneurship, as well as in theories by economists, entrepreneurs are often described as individuals with certain kinds of stable and enduring characteristics or features. The emphasis is on personality traits (Sexton and Foundation, 1986; Cromie, 2000). These traits presumably originate from early childhood and persist through their lifetime. Therefore learning and teaching are not relevant issues. The concept of this skill does not necessary imply a kind of innateness, rather the possibility of communication and change (Etzioni and Lawrence, 1991). Indeed the entrepreneurial literature until the mid 1980s focused on these innate traits as a way of identifying entrepreneurship. It was only after such critiques from (Chell, 1985; Gartner, 1988) that the direction of the research turned more to seeing entrepreneurship as an organizing practice. Of course, in the context of teaching, it is much easier to talk about learning in the connection of skills than in the connection of personality traits.

The business activity of a new firm is often developed as a part of the entrepreneur's personal life strategy, as a means of earning a living and is to a large extent characterized by the entrepreneur's personality characteristics. From the point of view of the trait theory, (McClelland, 1987) hypothesis can be seen as describing the characteristics needed in entrepreneurship. Economic risk taking, the power to decide whether to participate in economic commitments and the fact that personal income is dependent on the profit of the firm are factors which demand the personal characteristics of an achiever from the entrepreneur. The locus of control theory looks from various angles at the individual's ways of making sense of the social environment and the knowledge gained in different situations.

The entrepreneurial work culture is the composite of personal values, managerial skills, experiences and behaviors that characterize the entrepreneur in terms of one's spirit of initiative, risk propensity, innovative capacity and ability to manage a firm in relation to the economic environment (Covin and Slevin, 1991; McElwee and Robson, 2004; Schumpeter, 1934). (Morrison, 2000) found that the process of entrepreneurship initiation has its foundations in person and intuition and society and culture. It is much more holistic than simply an economic function and represents a composite of material and immaterial, pragmatism and idealism. Hence the essence of entrepreneurship is the application of innovatory processes and the acceptance of a risk-bearing function. Able to do so will bring about change of both a social and economic nature. Ideally, but not necessarily, the 
outcomes will have positive consequences. Carter and Jones-Evans (2006) also indicated that there was a significant relationship between entrepreneurship and cultural specificity, combined with an intuitive response by individual members of society, albeit part innate and part cultural conditioning. According to the Global Entrepreneurship Monitor's Report, the general attitude of the public toward entrepreneurship and the understanding and support of the importance of entrepreneurship in society are key social and cultural norms. The changes of work culture are important to improve the productivity of the organization and in this case the productivity of agriculture (Cheng et al., 2009). In the process to modernize the agricultural sector, the work culture is the main indicator, which needs to be taken into consideration. These changes involve information sharing and knowledge development among the workers (Pope, 2000). The variables that contribute to the success of small businesses are not unanimously agreed upon by researchers. Most entrepreneurial studies have concentrated on a few sets of variables: (1) The psychological and personality traits of entrepreneurs; (2) The managerial skills and training of entrepreneurs; and (3) The external environment. In a study conducted among Kenyan entrepreneurs found that the owner-manager's previous experience, an understanding of the needs of customers, access to capital and hard work were viewed as important success variables. Similarly, (Pratt, 2001) study of Kenyan entrepreneurs found the availability of capital, the possession of business skills, previous experience and the support of family members are essential for business success.

Ibrahim and Goodwin (1986) conducted a factor analysis of the variables contributing to successful small businesses in Canada and the United States. They found four success factors: entrepreneurial values, managerial skills, interpersonal skills and environmental characteristics. The entrepreneurial values were psychological in nature and included characteristics such as intuition, extroversion, attitude toward risk, flexibility and a sense of independence. Managerial skills included variables such as having a niche strategy, having an effective budget system, experience, education and a simple organization structure. The interpersonal skills factor was comprised of good customer relations, good employee relations and good interpersonal skills. Finally the environmental characteristics such as attractive interest rates, taxes and governmental assistance also play important roles in small business development.
In a recent study of small business owners in Pakistan, entrepreneurs rated three factors as particularly important to their success: hard work, good customer service and good product quality (Coy et al., 2007). Factors that were not considered important were government programs and training programs. Mohamed et al. (2011) also shared similar finding in the sense that informal entrepreneurship education is not able to provide the entrepreneurship skills acquisition as expected among Malaysian farmers. Thus extension and training courses should also focus on the fundamental changes in farmers' attitude towards agriculture as business. In a study of Turkish entrepreneurs, (Kozan et al., 2006) found that business management training and financing are significantly related to an SME owner's expansion plans. To be more specific, Turkish entrepreneurs need market information, technical assistance, information resources and training in finance and marketing to accumulate the resources necessary for expansion. Thus formal education in business or entrepreneurship has been recognized as an influencing factor affecting entrepreneurial growth in developing economies (Dickson et al., 2008; Gibb, 1996; Morrison, 2000). Therefore the objective of this study is to determine the influential factors that can be realized by the farmers in order to enhance their agri-entrepreneurship skills and traits.

\section{MATERIALS AND METHODS}

The survey was conducted in the middle of 2009 in order to gather information on the respondent's opinion and perception towards work culture among farmers. The farmers that were selected as respondents to this study are members of the Farmers Organization Authority (FOA) in Peninsular Malaysia. FOA is an agency under the Ministry of Agriculture and Agribased Industry which oversees 1,531 agri-based cooperative societies and 119 farmers associations through the country, serving the farmers in the rural areas FOA. One of the biggest farmers associations is the Farmers' Organization (FOs) which is cooperative based. Since Malaysia consists of 13 states, there are 13 states FOs and each of the states has their own district FOs. Thus the task of FOA is to register all the FOs under the states and one of the other functions of FOA is to provide training to the FOs members. Thus in this study we consider the farmers as FOA members. The structured questionnaire was designed to capture farmers' perception and opinion on good work culture in order to realize the government's aspiration to be competitive in the world market and to create and develop agri-entrepreneurs that could realize the 
aspiration of the government. A Likert scale of 1-5 (representing strongly disagree and 5 strongly agree) was used to measure the farmers' perception on 27 statements formulated in relation to work culture among agri-entrepreneurs. The samples of the population were farmers who are registered with FOA. The list of members from different states was obtained from FOA headquarters in Kuala Lumpur. The respondents were selected randomly from each state proportionately to the numbers of members in the particular state. In total 900 farmers were selected as respondents and 796 answered the questionnaires completely.

The collected data was analyzed using descriptive analysis. This describes the basic features of the data from the study. It describes the respondents' profile and their perceptions towards good work culture that can be used to enhance entrepreneurship skills among FOA members. Subsequently, factor analysis was carried out to determine the factors which promote a good work culture and are currently being realized by the FOA members in order to further re-inculcate these good practices amongst themselves. These elements are crucial for the success of FOA members to develop into agri-entrepreneurs and turn agriculture into a business which is in line with the inspirations of the Malaysian Ministry of Agriculture and Agri-based Industry.

\section{RESULTS AND DISCUSSION}

Descriptive analysis: Table 1 shows the demographic profile of the respondents from the 13 states of Peninsular Malaysia. Based on the location, the respondents were divided into 4 regions, North, East, Central and South. The Northern region was made up of 201 respondents $(25.3 \%)$, the Eastern region was comprised of 239 respondents (30.0\%), the Southern region amounted to 189 respondents (23.7\%) and the Central region equated to 167 respondents $(21.0 \%)$. In terms of age distribution, the majority of the respondents ( 377 or $47.40 \%$ ) were between 46 and 60 years old, $38.6 \%$ of them were between 31 and 45 years old, $8.30 \%$ of the respondents were more than 60 years old while another $5.8 \%$ were below 31 years old. The age distribution indicated that there were some young individuals out there that were interested in farming and agriculture. This is a good sign for the sector which will help in enhancing the entrepreneurship work culture among the FOA members. However, out of 796 respondents, $65.7 \%$ had only received a primary school education (6 years of schooling), while 31.3 had completed their secondary education (11 years of schooling), while those receiving tertiary education (Diploma/Degree) made up the remaining 3\%. Thus farmers are still not highly educated although most have gone through primary education. The low educational level among the farmers shows a need for informal agricultural education and extension courses which includes teaching sustainable farming practices, the management and care of livestock, using chemicals and fertilizers and dealing with pests and diseases in a sustainable way. On the other hand, in order to increase entrepreneurial skills farmers should be more familiar with the business aspects of farming and agribusiness, including accounting, record keeping, cost/benefit analysis, marketing and economics. Thus such informal training or courses can help to enhance the agrientrepreneurial skills of farmers. In terms of experiences in agriculture practices, the majority of the respondents had between 5-10 years of experience in agriculture to the participation in non-formal capacity building, the respondents who had participated between 2 and 4 times made up $37.40 \%$ of the respondents, $26.5 \%$ of the respondents had participated 5-7 times while 192 (24\%) had only participated just once.

Given the various backgrounds of the FOA members it would be interesting to find out from the farmers what they feel are the common factors that help encourage entrepreneurship skills and traits amongst themselves. Such skills and traits can be further reinculcated among the FOA members. This is important in order to realize the vision of MOA and to empower the FOA members with a new paradigm shift in following the vision of "agriculture is business".

Table 1: Demographic Profile of Respondents

\begin{tabular}{lcr}
\hline Characteristics & Number & $(\%)$ \\
\hline Region & 201 & \\
Northern region & 189 & 25.3 \\
Southern region & 167 & 23.7 \\
Central region & 239 & 21.0 \\
East region & & 30.0 \\
Age (year) & 46 & \\
$\leq 30$ & 307 & 5.8 \\
$31-45$ & 377 & 38.6 \\
$46-60$ & 66 & 47.4 \\
$\geq 61$ & 523 & 8.3 \\
Education level & & \\
Primary school & 249 & 65.7 \\
6 years of schooling) & & \\
Secondary school & 24 & 31.3 \\
(11 years of schooling) & \\
Tertiary education & 74 & 3.0 \\
Years of experience in & Agriculture (year) & \\
$\leq 5$ years & 393 & 9.3 \\
5 years to 10 years & 224 & 28.4 \\
11 years to 20 years & 105 & 13.2 \\
$\geq 20$ years & 192 & 24.1 \\
Number of times participating in non formal capacity building \\
$\leq 1$ \\
2-4
\end{tabular}


Am. J. of Economics and Business Administration 3 (3): 490-497 2011

Table 2: FOA Members perception towards entrepreneurial work culture concept

\begin{tabular}{|c|c|c|c|c|c|c|}
\hline \multirow[b]{2}{*}{ Statement } & \multicolumn{6}{|l|}{ Percentage } \\
\hline & Strongly disagree & Disagree & Neutral & Agree & Strongly agree & Mean \\
\hline I have a keen interest in my job and enjoy doing it & 0.1 & 1.3 & 1.6 & 45.0 & 52.0 & 4.50 \\
\hline I am fully responsible for all efforts that I have made & 0.0 & 0.1 & 1.6 & 50.8 & 47.5 & 4.46 \\
\hline $\begin{array}{l}\text { Under any circumstances, I will try my best } \\
\text { to raise my income level }\end{array}$ & 0.0 & 0.3 & 5.4 & 54.6 & 39.7 & 4.34 \\
\hline I put more emphasis on the quality of my products & 0.1 & 0.5 & 3.8 & 61.6 & 34.0 & 4.29 \\
\hline $\begin{array}{l}\text { I have enough capacity and recourses to cope with any } \\
\text { challenges and uncertainties }\end{array}$ & 1.9 & 5.0 & 7.4 & 49.9 & 35.8 & 4.13 \\
\hline
\end{tabular}

The FOA members' perception towards entrepreneurial work culture: With regard to the perception towards an entrepreneurial culture, it is apparent that an entrepreneurial culture needs to be closely aligned to entrepreneurial characteristics. The results in Table 2 show the perception of FOA members on some of the concepts of entrepreneurial culture. As can be seen, the highest mean score is 4.50 which shows that the farmers enjoy what they do and that they are highly interested in farming activities.

Previous studies show that entrepreneurship was facilitated by cultures that are high in individualism, uncertainty avoidance, innovation and creation and organization structure (Dimitratos and Plakoyiannaki, 2003; McDougall and Oviatt, 2000). The results presented in Table 2 show that FOA members were also concerned about entrepreneurship culture. Almost all of the respondents $(97.0 \%)$ claimed that they are fully responsible for all the effort that they have made. The Table also shows that more than $94.0 \%$ of them agreed to raise their income under any circumstances. Agreeing with the statement may imply the importance of innovation and a set of objectives as a goal to be achieved in their farming activities. Creating new ideas to make a farming business a commercial and beneficial venture indicates the orientation work culture of entrepreneurship among FOA members. The majority of the respondents put a lot of emphasis on a products' quality which indicates that the respondents are working systematically to perform well in their agricultural business activities. Dealing with uncertainties is one of the main characteristics of entrepreneurship. In this study about $85.7 \%$ of the respondents agreed with the statement which meant that this statement received the lowest overall score out of the five previous statements. Nevertheless the mean for this statement is above the average (4.13) and it shows that the respondents are willing to take risk and face uncertainty. Agreeing to some of the statements indicates that these FOA members are rational in their ways of doing things and behave like any other entrepreneur. This indicates that there are some components of an entrepreneurship work culture that have already been inculcated among the FOA members. Realizing these entrepreneurship skills and traits is an important indicator for further enhancing entrepreneurial development.

Factor analysis: Factor analysis was performed to determine the underlying work culture factors that are perceived by FOA members as enhancing their agrientrepreneur development, capacity building and ability to empower themselves in realizing the objectives of the government policy in increasing food production. As indicated earlier several questions were posted to the respondents. These questions are reduced into several variables that could explain the work culture realized by FOA members to be adhered to in order to be successful agri-entrepreneurs. The reliability of the survey instrument was deemed satisfactory since the Cronbach alpha for the variables is high (0.854). Thus, the results of this statistical analysis show a strong convergence of validity. This is shown by the initial tests performed on the statements which included the Bartlett's test of sphericity and the Kaiser-Meyer- Olkin (KMO) test of sampling adequacy. The tests confirm the appropriateness of conducting factor analysis (Tabachnick and Fidell, 2007). The KMO test for the set of predetermined variables reached values of at least 0.84 , which indicated sampling adequacy and permitted factor analysis to be carried out using the 27 statements. The six factors which account for $60.681 \%$ of total variance are summarized as follows (Table 3 ).

Table 3 shows the factors generated fron the estimation of factor analysis. The first factor was innovation, which consisted of four sub-variables and had a total variance of $25 \%$. Able to try new technology needed to become successful as agrientrepreneur has the highest factor loading (0.719). This is followed by I like to try new innovations (0.712), exploring new opportunities can be a key success factor (0.707) and increasing knowledge and skills may bring me some new agrientrepreneurship ideas (0.656). The results show that in order for FAO members to be successful they have to depend on their creativity and innovativeness. 
Am. J. of Economics and Business Administration 3 (3): 490-497 2011

Table 3: Results of factor analysis

\begin{tabular}{|c|c|c|}
\hline Factors and sub-variables & Sub-variables loading & $\begin{array}{l}\text { Variance (\% of explained }) \\
\text { Eigenvalues }\end{array}$ \\
\hline Innovative & & 24.931 \\
\hline Able to try new technology needed to become a successful agri-entrepreneur & 0.719 & \\
\hline I like to try new innovations & 0.712 & \\
\hline Exploring new opportunities can be the a key success factor & 0.707 & \\
\hline Knowledge and skill may bring some new agri-entrepreneurship ideas & 0.656 & \\
\hline Risk taking propensity & & 11.385 \\
\hline I am prepared to take risk & 0.745 & \\
\hline I bear all the uncertainty in my business & 0.629 & \\
\hline Confronting risky situations is part of the nature of being an entrepreneur & 0.619 & \\
\hline An entrepreneur should be a risk taker not risk averse & 0.500 & \\
\hline Profit oriented & & 6.820 \\
\hline I try to find ways to increase income & 0.714 & \\
\hline I'm able to create new ideas in order to increase profits & 0.680 & \\
\hline I am positive in 5 years I can multiply my income & 0.680 & \\
\hline Visionary & & 6.700 \\
\hline Open to communication and sharing information is what I always do & 0.772 & \\
\hline I always think of how to make the most of opportunities before they happen & 0.645 & \\
\hline One of my principals to increase productivity & 0.558 & \\
\hline Managerial skills & & 5.577 \\
\hline I always plan what I want to do according to the schedule & 0.830 & \\
\hline $\begin{array}{l}\text { Agri-entrepreneurs should have commercial, social and political characteristics } \\
\text { which help them to succeed }\end{array}$ & 0.585 & \\
\hline Self confidence & & 5.268 \\
\hline $\begin{array}{l}\text { I feel proud if my agricultural product fulfills the characteristic } \\
\text { of a quality product }\end{array}$ & 0.689 & \\
\hline I strongly believe that my business can contribute to the food industry & 0.552 & \\
\hline I have the capability and enough resources to face any challenges in agriculture & -0.584 & \\
\hline Total Variance explained & & 60.681 \\
\hline
\end{tabular}

Besides this, help from the government in the form of training, skill building and motivation can create innovativeness among the FOA members.

Risk taking propensity was recognized as the second factor. The statement I am prepared to take risks has the highest factor loading (0.745) followed by I bear all the uncertainty in my business (0.629). The factor loadings for Confronting risky situations is part of the nature of being an entrepreneur and an entrepreneur should be a risk taker, not risk averse are 0.619 and 0.500 respectively. The result shows that the FOA members generally agree on the nature of the business they are in, which is very risky and has a high probability of failure. Thus the risk taking characteristic is a very important part of the work culture. The analysis shows that this entrepreneurial trait has been recognized by the farmers which are a promising sign as re-inculcating this trait among the farmers is very important. If none of these FOA members are willing to take risks in what they are doing, agriculture will not move forward.

The third factor was being profit oriented which had a variance of 6.820 and consists of 3 sub-variables; I try to find ways to increase my income has the highest factor loading (0.714) followed by I am able to be creative in order to increase profits $(0.680)$ and I am sure I can multiply my income in 5 years $(0.588)$. Profit making is one of the farmer's aims and farmers are very rational in this case. They will always try to find ways to increase their income. Therefore they must be willing make any sacrifice to make the project that they are doing successful and to achieve their target.

The fourth factor was being visionary which had a total variance of 6.700 and comprised of 3 subvariables. Always being open to communicating has the highest factor loading (0.772) followed by I think of how to make the most of opportunities before they happen (0.645) and one of my principals is to increase productivity (0.558). FOA members realized that having a vision and a mission for what they are doing is very important for their future success, thus allowing them to be more focused in accomplishing their goals.

Managerial Skills was the fifth factor, which consisted of two sub-variables and has a total variance of $5.577 \%$. The factor loading for my plans are always based on a schedule for everything is 0.830 while the factor loading for agri-entrepreneurs should have commercial, social and political characteristics which help them to succeed is 0.585 . One of the factors identified by the FOA members is possessing managerial skills. Thus the farmers seem to understand that acquiring managerial skills is a plus factor which helps them to achieve their goal of becoming successful agri entrepreneurs. Agribusiness planning is an essential tool for the farmers as it gives them the ability 
to organize, implement, monitor and adjust their farm activities. This is another crucial factor which demands farmers to see agriculture as a business.

The last factor is self confidence which scored a total variance of 5.268 and was comprised of 3 subvariables. Feeling proud if their product fulfills the characteristics of a quality product has the highest factor loading (0.689) followed by I strongly believe that my business can contribute to the food industry (0.552) and I have the capability and enough resources to face challenges (0.584). An entrepreneur should be able to seek out and complete demanding tasks. It is unlikely to happen if they have little confidence in themselves. Hence the inculcation of self confidence in FOA members is a very important factor as it allows the farmers to face the challenges in their business activities.

\section{CONCLUSION}

This study explores various dimensions of FOA members with regards to the work culture and traits which they have realized themselves. The identification of these characteristics can be used to further enhance and develop entrepreneurial skills among the FOA members in order for them to become successful agrientrepreneurs. The factor analysis has determined six factors as realized by the FOA members. Factors such as innovativeness, risk taking propensity, being profit oriented and visionary, working systematically and having self confidence are some of the factors that have been generated from the factor analysis. Similar factors but from a different perspective were also reported by (Sexton and Foundation, 1986; Cromie, 2000; Gurol and Atsan, 2006). These factors can be used as a basis for motivating actions that help stimulate setting up an agri-entrepreneurship work culture, as well as promoting capacity building and empowerment among the FOA members. Studies have indicated that entrepreneurship work culture cannot be built as it comes from the personality traits of the individuals (Thomas and Mueller, 2000). Nevertheless, it is not impossible for individuals who are already in the business of farming to inculcate these traits in themselves. Besides this, other researchers have recognized that formal education systems or informal education (training and short courses) is a strong factor which contributes to the growth of entrepreneurial capabilities (Dickson et al., 2008; Gibb, 1996; Morrison, 2000). Since most of the FOA members are not highly educated, the fact that these farmers are aware of these agri-entrepreneurial skills is very important. Hence, the ability of the farmers to inculcate these dimensions of entrepreneurial work culture may not take that much effort, especially among the younger FOA members. This provides some optimism as inculcating an entrepreneurial work culture will help empower the farmers to become more business minded. Motivation, encouragement, moral support and by providing relevant informal or formal training, market outlets and establishing networks could trigger the desire to become a successful agri-entrepreneur.

It is not expected that all FOA members could install these entrepreneurial skills and traits. The focus should be on the younger members and the ones that have undergone secondary and tertiary education. Nevertheless, all of the farmers have the potential to develop into successful agri-entrepreneurs as these farmers have realized their entrepreneurship skills and traits. These insights are essential if one wants to evaluate and improve the entrepreneurship capability of the FOA members. Thus, a work culture which promotes agri-entrepreneurship and agricultural skills is important and can act as one of the drivers for the agriculture sector to move forward and become the new engine of growth for the Malaysian economy. In this regard, efforts should be intensified to encourage agricultural entrepreneurs with training to focus not only on modern technologies and equipment but also on fundamental changes in attitudes towards farming. These attitudes should take the form of farmers viewing farming not as a way of life but rather as a business and that farmers are not only acting as producers but also as entrepreneurs. The reinculcation of an agri-entrepreneurial work culture in training activities is very important for developing the necessary skills and traits. Training activities to be undertaken should focus on changing the mind sets and attitudes of the farmers so they are able to participate more effectively in modern and commercially oriented agricultural activities, as well as, in modern farming practices, post harvest handling, processing and marketing.

Limitation of study: This study focuses on entrepreneurial work culture practiced among FOA agri-entrepreneurs. Therefore the questionnaires were distributed only to farmers who are registered with FOA and involved in crops cultivation. There is not causal statement in this study because the nature of the research is an exploratory research. The survey was conducted in Peninsular Malaysia only due to the time and cost limitations. Hence there is a need for further research on agri-entrepreneurship work culture in the entire regions in Malaysia (including Sabah and Sarawak) beyond what they grow, process and work. 
Am. J. of Economics and Business Administration 3 (3): 490-497 2011

\section{ACKNOWLEDGEMENT}

The researchers would like to thank university Putra Malaysia (UPM) for granting Research University Grants (RUGS) to undertake the study for the period of 2 years (December 2008-January2011).

\section{REFERENCES}

Carter, S. and D. Jones-Evans, 2006. Enterprise and Small Business: Principles, Practice and Policy. 2nd Edn., Trans-Atlantic Pubns, Harlow, England, New York, ISBN: 027370267X, pp: 572.

Chell, E., 1985. The entrepreneurial personality: A few ghosts laid to rest? Int. Small Bus. J., 3: 43-54. DOI: $10.1177 / 026624268500300303$

Cheng, M.Y., W.S. Chan and A. Mahmood, 2009. The effectiveness of entrepreneurship education in Malaysia. Educ. Train., 51: 555-566. DOI: 10.1108/00400910910992754

Covin, J.G. and D.P. Slevin, 1991. A conceptual model of entrepreneurship as firm behavior. Entrepreneurship Theory Practice, 16: 7-25. Available from: DOI: 10.1007/BF00382966

Coy, S.P., M.F. Shipley, K. Omer and R.N.A. Khan, 2007. Factors contributory to success: A study of pakistan's small business owners. J. Dev. Entrepreneurship, 12: 181-198.

Cromie, S., 2000. Assessing entrepreneurial inclinations: Some approaches and empirical evidence. Eur. J. Work Organ. Psychol., 9: 7-30. DOI: $10.1080 / 135943200398030$

Dickson, P.H., G.T. Solomon and K.M. Weaver, 2008. Entrepreneurial selection and success: Does education matter? J. Small Bus. Enterprise Dev., 15: 239-258. DOI: $10.1108 / 14626000810871655$

Dimitratos, P. and E. Plakoyiannaki, 2003. Theoretical foundations of an international entrepreneurial culture. J. Int. Entrepreneurship, 1: 187-215. DOI: 10.1023/A:1023804318244

Etzioni, A. and P.R. Lawrence, 1991. Socio-economics: Toward a New Synthesis. 1st Edn., M.E. Sharpe, Armonk, New York, ISBN: 0873326857, pp: 359.

Gartner, W.B., 1988. Who is an entrepreneur? Is a wrong question? Am. J. Small Business, 12: 11-32.

Gibb, A.A., 1996. Entrepreneurship and small business management: Can we afford to neglect them in the twenty-first century business school? Bri. J. Manage., 7: 309-321. DOI: 10.1111/j.14678551.1996.tb00121.x
Gurol, Y. and N. Atsan, 2006. Entrepreneurial characteristics amongst university students: Some insights for entrepreneurship education and training in Turkey. Educ. Train., 48: 25-38. DOI: 10.1108/00400910610645716

Ibrahim, A.B. and J.R. Goodwin, 1986. Perceived causes of success in small businesses. Entrepreneurship: Theory Practice, 11: 41-50.

Kozan, M.K., D. Oksoy and O. Ozsoy, 2006. Growth plans of small businesses in Turkey: Individual and environmental influences. J. Small Bus. Manage., 44: 114-129. Available from: DOI: $10.1111 / \mathrm{j} .1540-$ 627X.2006.00157.x

McClelland, D.C., 1987. Characteristics of successful entrepreneurs. J. Creative Behav., 21: 219-233.

McDougall, P.P. and B.M. Oviatt, 2000. International entrepreneurship: The intersection of two research paths. Acad. Manage. J., 43: 902-908. DOI: $10.2307 / 1556418$

McElwee, G. and A. Robson, 2004. The entrepreneurial farmer in Lincolnshire: some theoretical observations. In: National Rural Policies and Entrepreneurship in The Rural Context, University of Helsinki Finland.

Mohamed, Z., G. Rezai and M.N. Shamsudin, 2011. The effectiveness of entrepreneurship extension education among the FOA members in Malaysia. Current Res J. Soc. Sci., 3: 17-21.

Morrison, A., 2000. Entrepreneurship: what triggers it? Int. J. Entrepreneurial Behav. Res., 6: 59-71. DOI: $10.1108 / 13552550010335976$

Pope, J., 2000. Confronting Corruption: The Elements of a National Integrity System. 1st Edn., Transparency International, Berlin, London, ISBN: 3980565785, pp: 364.

Pratt, V., 2001. Sharing Business Skills in Kenya. Center for International Private Enterprise, Washington, DC.

Schumpeter, J.A., 1934. The Theory of Economic Development: An Inquiry into Profits, Capital, credit, Interest, and the Business Cycle. 1st Edn., Transaction Publishers, New Brunswick, NJ., ISBN: 0878556982, pp: 255.

Sexton, D.L. and R.G.K. Foundation, 1986. The Art and Science of Entrepreneurship. 1st Edn., Ballinger Pub. Co., Cambridge, Mass., ISBN: 0887300707, pp: 422.

Tabachnick, B.G. and L.S. Fidell, 2007. Using multivariate statistics. 5th Edn., Pearson and Allyn and Bacon, Boston, ISBN: 0205465250, pp: 980.

Thomas, A.S. and S.L. Mueller, 2000. A case for comparative entrepreneurship: Assessing the relevance of culture. J. Int. Bus. Stud., 31: 287-301. 